\title{
Feeding Everyone: Solving the Food Crisis in Event of Global Catastrophes that Kill Crops or Obscure the Sun
}

\author{
David C. Denkenberger ${ }^{a *}$, Joshua M. Pearce ${ }^{b}$
}

a* Global Catastrophic Risk Institute, 2345 Forest Ave, Durango, CO, USA 81301; 970-4031792; david.denkenberger@gmail.com.

${ }^{\mathrm{b}}$ Department of Materials Science \& Engineering and Department of Electrical \& Computer Engineering; Michigan Technological University, 601 M\&M Building, 1400 Townsend Drive, Houghton, MI, USA 49931; pearce@mtu.edu.

\begin{abstract}
Mass human starvation is currently likely if global agricultural production is dramatically reduced for several years following a global catastrophe: e.g. super volcanic eruption, asteroid or comet impact, nuclear winter, abrupt climate change, super weed, extirpating crop pathogen, super bacterium, or super crop pest. This study summarizes the severity and probabilities of such scenarios, and provides an order of magnitude technical analysis comparing caloric requirements of all humans for five years with conversion of existing vegetation and fossil fuels to edible food. Here we present mechanisms for global-scale conversion including: natural gas-digesting bacteria, extracting food from leaves, and conversion of fiber by enzymes, mushroom or bacteria growth, or a two-step process involving partial decomposition of fiber by fungi and/or bacteria and feeding them to animals such as beetles, ruminants (cattle, sheep, etc), rats and chickens. We perform an analysis to determine the ramp rates for each option and the results show that careful planning and global cooperation could maintain humanity and the bulk of biodiversity.
\end{abstract}

Key index words/phrases: Risk; moral hazard; chemosynthetic bacteria; fishing; extinction; cellulosic biofuels

\section{Introduction}

It is widely assumed that if agricultural production is dramatically reduced over a period of years, this will cause mass human starvation or even extinction. This could be effected by any of six crop-killing scenarios: 1) abrupt climate change [1], 2) super weed [2], 3) extirpating crop pathogen [3], 4) complete loss of bees [4], 5) super bacterium [5], or 6) super crop pest [6], or three sun-obscuring scenarios 1) asteroid or comet impact [7], 2) a super volcanic eruption ${ }^{1}$ [7], or 3) nuclear winter [8]. The sun-obscuring scenarios are the most challenging to overcome. The penetration of solar energy into our traditionally defined primary (raw input) energy use, through technologies like photovoltaics (solar cells) and solar heating, is only order of magnitude (order) $1 \%$ [9]. However, if we define primary energy more broadly to include the solar energy required to grow humanity's food, feed and forest products, the solar fraction of primary energy is closer to $99.9 \%$ [9]. Thus, if the sun were mostly blocked for a period of years it would seem to be an insurmountable task to replace this solar energy, which is three orders of magnitude greater than global fossil-fuel energy consumption.

\footnotetext{
${ }^{1}$ We consider continental basalt flows as a subset of the volcanism category.
} 
This paper summarizes these risks and quantifies their severity and probabilities where possible. It also provides a technical analysis, accurate within an order of magnitude, to investigate the challenge of supplying five years of all humanity's caloric requirements by converting existing vegetation and fossil fuels to edible food products. Mechanisms investigated for the necessary global-scaled conversion include: natural gas consuming bacteria, food extraction from leaves, and conversion of fiber (plant material that humans cannot digest) via industrial methods, organisms consumed by humans, or a two-step process involving partial decomposition from bacteria or fungi fed to animals. We performed an analysis to determine the ramp rates for each of these options, and we discuss results to provide information for planning and policy to enable feeding humanity even as existing food stocks are depleted.

The non-climate altering catastrophes (2-6 above) are generally less serious, and the literature contains fewer quantitative estimates of their impact and probabilities. The current global crop losses are weeds (9\%), pathogens (15\%) and animal pests (11\%) [10]. Although some super weeds have acquired immunity to an herbicide [11], they can be controlled by other herbicides or tilling the weeds underground. However, there are greater threats of the super weeds releasing toxins or having considerably higher photosynthetic efficiency [2] and therefore overwhelming conventional control. There is also a rising concern about the susceptibility to pests and pathogens of crops with limited genetic variability [6] and the potential for engineered pathogens that target multiple species [12]. Again, although the literature defines a super pest as an animal that has acquired pesticide resistance [6], other pesticides or natural methods of control can mitigate this risk. An animal could also become so much more powerful that it overwhelms conventional methods of control. A super bacterium refers to a bacterium that disrupts growing conditions for plants by altering soil chemistry or disrupting beneficial bacteria [5]. It is unlikely that a single organism represents a global threat, as each would probably not be able to compete in all of the agricultural climates. However, a coordinated terrorist attack of multiple organisms could represent a global threat.

The spread of these super organisms would likely be similar to the spread of invasive species (unless there is a coordinated terrorist attack). Though the warning for asteroids (largely between Mars and Jupiter) could be centuries, there would generally be considerably less than one year of warning for comets (originating outside the solar system), super volcanic eruptions, and nuclear wars. Earth has undergone dramatic temperature fluctuations in the past, with $10^{\circ} \mathrm{C}$ regional changes in one decade [1]. As anthropogenic greenhouse gas emissions destabilize the global climate [13], abrupt climate change could become more intense [14]. Thus, this represents a global agricultural threat and the three sun-obscuring scenarios pose an even graver threat (Table 1) [9].

Table 1. Probability, severity and intensity of catastrophes [9].

\begin{tabular}{|llllll|}
\hline Catastrophe & $\begin{array}{l}\text { Probability } \\
\text { (per year) }\end{array}$ & $\begin{array}{l}\text { Maximum Food } \\
\text { Production Loss } \\
(\%)\end{array}$ & $\begin{array}{l}\text { Agricultural } \\
\text { Loss Velocity } \\
(\% / y r)\end{array}$ & $\begin{array}{l}\text { Time to } \\
\text { Recovery } \\
(\mathbf{y r})\end{array}$ & $\begin{array}{l}\text { Qualitative } \\
\text { Intensity }\end{array}$ \\
$\begin{array}{l}\text { Abrupt } \\
\text { climate } \\
\text { change }\end{array}$ & 1 in 1,000 & 10 & 1 & 100 & Medium \\
\hline
\end{tabular}


Preprint: DC Denkenberger \& JM Pearce, Feeding Everyone: Solving the Food Crisis in Event of Global Catastrophes that Kill Crops or Obscure the Sun. Futures 72: 57-68 (2015). DOI:http://dx.doi.org/10.1016/j.futures.2014.11.008

\begin{tabular}{|llcccc|}
$\begin{array}{l}>\mathbf{1 ~ k m} \\
\text { asteroid or } \\
\text { comet }\end{array}$ & $\begin{array}{l}1 \text { in } \\
1,000,000\end{array}$ & 100 & 100 & $3-10$ & High \\
$\begin{array}{l}\text { Super } \\
\text { volcanic } \\
\text { eruption }\end{array}$ & 1 in 100,000 & 100 & 100 & 3 & High \\
$\begin{array}{l}\text { Nuclear } \\
\text { winter }\end{array}$ & 1 in $1,000^{2}$ & 100 & 100 & 10 & High \\
\hline
\end{tabular}

Problems such as slow climate change, loss of fisheries, species extinction, loss of bees, loss of unsustainable irrigation, loss of artificial pesticides and fertilizers, loss of topsoil, salinization of soil, desertification, current loss of stratospheric ozone, water pollution and other resource exhaustion issues are less serious because of a smaller and/or slower impact on global food production. This analysis considers the scenario of no increased effort to prevent these problems. Slow climate change occurs over a century or more, allowing adaptations such as relocating crops and humans. Global fisheries make up less than 3\% of human calories ([9]; not all parts of the fish are currently consumed). Biodiversity supplies ecosystem services to agriculture (e.g. pollination, pest control, soil fertility, climate stability) [17]. All of these issues are elsewhere in this section, and so there does not appear to be a credible route to agricultural supply collapse, though loss of wild species is important for the species' intrinsic value. Extinction of one species can cause the extinction of additional species. For example, animals that pollinate or disperse the seeds of plants could cause cascading extinction in the plants [18]. In addition, the loss of a plant species could cause the extinction of a specialist animal feeder. However, there are plants that are not dependent on animals, so the biomass and soil in natural ecosystems are likely to be mostly maintained despite cascading extinctions. Therefore, the impact on agriculture is likely to be small. The following quote is often misattributed to Einstein: "If the bee disappears from the surface of the earth, man would have no more than four years to live.”, which greatly overstates the value of pollinators. The total loss in agricultural production for a loss of all animal pollinators is only 3-8\% [4]. Though this percentage is growing, not all animal pollinators are bees. Therefore, the complete loss of bees would not be an agricultural catastrophe of the magnitude focused on in this paper. Total water consumption for food production including rain fed crops and grazing is 14,000 billion tons (Gt)/yr [19]. Irrigation consumption is $1200 \mathrm{Gt} / \mathrm{yr}$, about 1/3 of this being unsustainable [20]. Therefore, losing all unsustainable irrigation would only be a 3\% loss in food production. Furthermore, it would take decades for this to occur. Not all pesticides are petroleum-based [10], and it is possible to synthesize petroleum substitutes from renewable hydrogen (via electrolysis: electric water splitting) [21]. The dominant production method for nitrogen fertilizer is combining hydrogen with atmospheric nitrogen [22], and renewable energy can provide this hydrogen. There are a variety of solutions for the supply of phosphorus and other mineral fertilizers. Many solutions

${ }^{2}$ One estimate of the chance of full-scale nuclear war is $\sim 1 \% / \mathrm{yr}$ and it uses conditional probabilities [15]. Another estimate is $\sim 1 \% / \mathrm{yr}$, based on analysis of the possibility of U.S. or Russian launches in response to false alarms in their early warning systems [16]. Then we conservatively estimate that there is only a 1 in 10 chance of full-scale nuclear war causing nuclear winter. 
are similar to the solutions to a food shortage [9], such as reducing food waste, food fed to animals, land planted with non-food items, and land planted with lower caloric efficiency foods. Other solutions involve recycling, such as from wood-burning ash. Additional mining options include landfills (which could involve extracting the paper, wood, etc., converting the energy and reclaiming the minerals) and even mining commonly occurring rock [23]. Loss of topsoil, salinization of soil, desertification, current loss of stratospheric ozone, and water pollution are relatively slow processes. There are many other mineral inputs to agriculture, e.g. copper for motors. However, options for dealing with a shortage include recycling, substituting, mining landfills, and mining commonly occurring rock. Overall, these less serious problems do deserve study, but the solutions are more straightforward than for the catastrophes that are the focus of this paper.

Super pests or microbes could cause considerably more food spoilage than the current pest/microbe scenario. Though many of the solutions presented in this paper could ameliorate an increased food spoilage problem, there are more direct solutions that are outside the focus of this paper [9].

Many of these catastrophes would reduce agricultural productivity $<\sim 70 \%$, so the technical solution for feeding the entire world's population would be to reduce the amount of pre-harvest losses (e.g. from pests and weeds), the yield underachievement (e.g. not enough fertilizers and not the best plant varieties), wasted food from distribution and at households, and edible food turned into biofuels and fed to livestock and pets [9]. As the severity of a catastrophe increases, this would require more extreme measures to prevent widespread starvation. For example, in a full-scale nuclear winter simulation, the maximum global temperature reduction was $9^{\circ} \mathrm{C}$ [8], referred to here (rounded) as the $10^{\circ} \mathrm{C}$ catastrophe. Farmers could grow a considerable amount of food after the crisis first starts as there is a lag before temperature and ozone are fully reduced $[8,24]$. This, coupled with food storage, would provide full human food (1.5 billion tons $(\mathrm{Gt}) / \mathrm{yr}$ ) for the first year [9] and allow other sources to be ramped up ("slow food"). However, if nearly all the sunlight is blocked and therefore the temperature drop would be roughly double (the $20^{\circ} \mathrm{C}$ catastrophe - see Section 2.2), the additional crop would be negligible. If the catastrophe hit at maximum food storage, the storage would be approximately 11 months of food [9]. The worst-case scenario of the $20^{\circ} \mathrm{C}$ catastrophe hitting at minimum food storage time with little warning would require nonconventional food in less than one year: "fast food."

We focus on feeding the entire global population for a five-year time horizon because some of the less promising solutions are likely to produce an important amount of food after five years, and some catastrophes last less than five years.

\section{Calculation/Results}

\subsection{Solutions Introduction}

Increased food storage represents the primary solution previously proposed to this set of catastrophes for feeding all people [7]. This solution is not viable in the near term and would exacerbate existing levels of mortality due to inadequate global access to affordable food. Due to malnutrition and hunger-related disease, $\sim 6$ million deaths/yr occur in children under five years old [25]. Note that the technical solution to feeding people now is much less challenging than feeding people during a catastrophe. This shows that the economics and politics of feeding people in a catastrophe is important future work. 
For the purposes of determining all scenarios, we assume that the entire current global population, biomass (by dry weight) and infrastructure are intact. Some catastrophes would kill people, burn or radioactively contaminate regional biomass, and destroy infrastructure, but the difficulty of the problem would be similar. There are several considerations that would shrink the scope of the problem. First, for the crop-killing scenarios, if only certain species or geographic regions are affected, other crops or areas could be substituted (and food may be extracted from the super weed or pests (see Section 2.4)). Even in some sun-obscuring scenarios, growing some food with remaining natural light is possible [9].

Currently $\sim 0.1 \%$ of the ocean area undergoes coastal upwelling bringing nutrients to the surface, but it produces $\sim 50 \%$ of the global fish catch because of the high nutrient levels [26]. A similar effect would occur when a sun-obscuring catastrophe cools the upper layers of the ocean and they sink. Therefore, since the ecosystem would be shielded from the UV, the marine caloric contribution could be more than a year's worth of food [9]. After the cooling upwelling stops (and for all time in the crop-killing scenarios) macronutrient fertilization of the ocean could provide full human food (Figure 1) [9]. However, for the more extreme catastrophes in which $90 \%$ or more of the light is blocked, temperatures would be even lower and photosynthesis would be severely limited, so another solution is required and here we investigate the solutions utilizing stored biomass and fossil fuels.

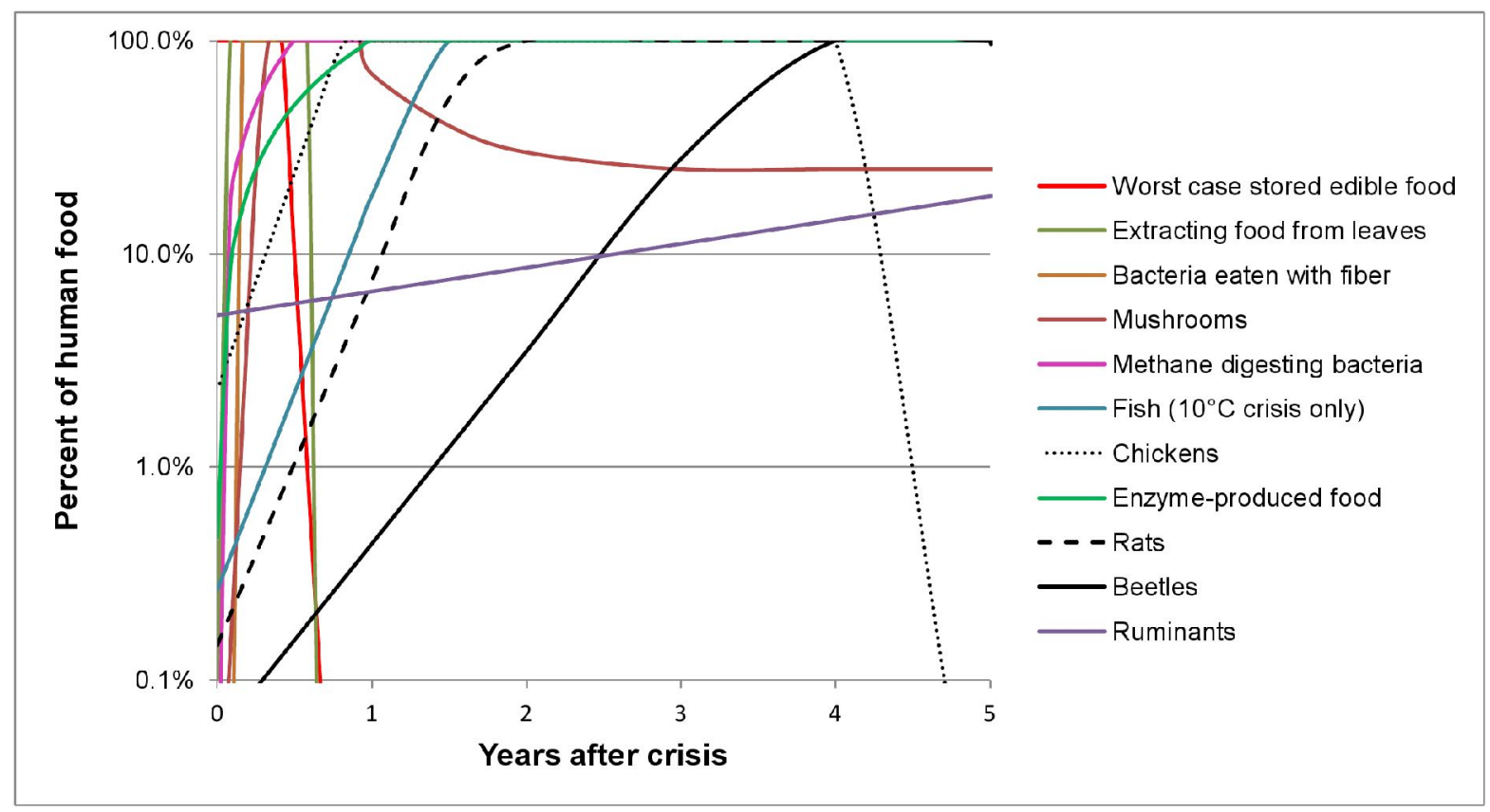

Figure 1 (color in print). Approximate food supply over time from the 11 most promising sources. The sources are ordered by when they first reach $100 \%$ of food. Many of these food sources are not independent of each other and one cannot simply add them. The independent groups are stored food, methane bacteria, fast food (generally non-woody biomass-sourced), slow food with animals (wood sourced), wood converted to bacteria and enzyme-produced food (the latter two are high efficiency, so little competition for biomass). Even within these groups, assuming biomass supply is adequate, there are some independent routes to full food supply. 
There is very large uncertainty in these numbers, so the primary purpose is to illustrate the magnitudes and trends. The least certain are rats and chickens, dotted.

\subsection{Fiber Supply for Conversion to Food}

The stock of dry biomass in vegetation is approximately $1200 \mathrm{Gt}$ [27]. Global tree harvest (roundwood) is 3 billion $\mathrm{m}^{3}$ [28], so with a dry density of 0.5 tons $/ \mathrm{m}^{3}$ [29], this is 1.5 $\mathrm{Gt} / \mathrm{yr}$. In the $10^{\circ} \mathrm{C}$ catastrophe case, roughly half of this vegetation would be in areas that did not freeze [9]. The peak temperature response is roughly proportional to the peak reduction in shortwave (solar) radiation for both the sulfate [30] and soot [8] catastrophes. Therefore, in the $20^{\circ} \mathrm{C}$ catastrophe, roughly half of the tropical forests would remain above freezing [8].

Utilization of current chainsaws could fell approximately 500 Gt dry of trees/yr [9]. However, given that $\sim 40 \%$ of the total mass of wood is above ground, the chainsaw total is considerably greater than the tropical forests ( $170 \mathrm{Gt}$ above ground [27]). In the $20^{\circ} \mathrm{C}$ catastrophe, freight capacity could transport logs from unfrozen zones, but this would only facilitate outdoor mushrooms, which is not a complete solution. Therefore, humanity would probably use the transportation capability for other food sources instead, which should be feasible [9]. Chipping all the fiber would take a small percentage of humanity's current energy use, and it should be feasible to retrofit light-duty vehicle factories to produce wood chippers that could chip sufficient wood within one year [9]. Once the trees die and dry out, they would be more susceptible to fire, which would require a considerable but feasible ramping up of current fire suppression capabilities [9].

Since we show below that there is sufficient methane and accessible above-ground wood for the food supply for five years, humanity would not have to utilize less desirable fiber sources. These include below-ground wood, soil carbon (including peat), landfills, houses, and hydrothermal vents.

\subsection{Stored Biomass/Fossil Fuel Conversion}

Generally for the solutions outlined here, we halved the ideal efficiency to take into account practical difficulties. We also generally take the square root of the ideal population growth rate because when there are a large number of offspring, a smaller fraction would be feasible to save. Fossil fuels could provide sufficient feedstocks for synthetic food production [9]. A hybrid industrial/biological technique would be providing chemicals industrially to chemo-synthesizing bacteria (those that use a chemical as a food source) [9]. A further possible solution is growing food with artificial light [9]. However, all three of these scenarios have the difficulty of ramping up industrial capacity, except for bacteria oxidizing methane. This latter solution would only require retrofitting to low temperature, pressure, and corrosion bioreactors (vessels that facilitate organism growth), and we estimate this could achieve full food in 6 months (Figure 1) [9]. Enzymes and acid can convert lignocellulose (fiber) to sugar [31] (industrial digestion). Full food could be produced by enzyme digestion in about a year (Figure 1) [9].

Ruminants, such as cattle, sheep, and goats, have the ability to digest cellulose [32]. These already make up a considerable fraction of our calories, but they are limited in their doubling time. Wood that has been partially decomposed by mushrooms is already being fed to cattle, sheep, and bison [33]. Other numerous large grazers include horses and deer. Even pigs can digest half of pure cellulose feed [34]. Rabbits can also digest cellulose, and double much 
faster, but currently have a much smaller initial food production. These all could be partial solutions, but it would not save all the people. We estimate $5 \%$ initial food and $30 \%$ growth rate for ruminants (Figure 1) [9].

Outdoor mushroom growth on logs has a realistic efficiency of 1\% [9]. As $10 \mathrm{~cm}$ diameter logs are consumed in $\sim 4$ years, only about $70 \%$ of the mass of trees cut down could be consumed in 4 years. Thus, $700 \mathrm{Gt}$ of dry wood would have to be prepared in one year, which does not appear to be feasible from a wood supply perspective. Ramping is not a constraint because of billions of spores per mushroom. Therefore, Figure 1 shows mushrooms supplying only roughly $25 \%$ of human food for the longer-term (we cover short-term mushrooms in "Stopgap Food Production: Fast food"). The $20^{\circ} \mathrm{C}$ catastrophe would have lower longer-term mushroom production because of less wood above freezing (not shown).

Beetles digesting lignocellulose would have a realistic efficiency of 6\% [9]. For most cellulose-digesting beetles, the wood would need to be softened, and ideally have the lignin removed. Grinding (to small particles) capacity is insufficient, though chipping and industrial lignin removal would be feasible with some ramping [9]. Another option is partial digestion by fungi. Since white rot fungi (including mushrooms) preferentially digest lignin [35], if they consume $20 \%$ of the calories of the wood at 5\% efficiency, this would leave $\sim 80 \%$ of the calories in the wood (similar to the industrial lignin removal scenario). If the cellulose-digesting beetles have an efficiency of $6 \%$, this would be overall $~ 5 \%$ conversion efficiency from wood to animal [9].

The initial stock of cellulose-digesting beetles is sufficient to provide $\sim 0.05 \%$ of human food and with a realistic growth rate for the $10^{\circ} \mathrm{C}$ catastrophe, this is a factor of eight growth in one year [9]. Therefore, it would take $\sim 4$ years to reach full human food (Figure 1 ). With a $20^{\circ} \mathrm{C}$ catastrophe, it is unlikely that the beetles could reproduce; however, chipping the logs and moving them indoors could provide a workaround.

In natural ecosystems, bacteria make lignocellulose available to non-cellulose digesters (e.g. fish eating rotten leaves) [36]. Similarly, we propose to use fungi and bacteria to process fiber for digestion by rats and chickens. Humans already consume rats, and there is evidence that rats can digest cellulose [37] [9]. Having rats eat wood that has had the lignin reduced by fungi and most of the cellulose and hemicellulose (another type of fiber) converted into bacteria (with fertilization such as nitrogen) would have an overall efficiency of $~ 4 \%$ [9]. Fertilizer supply should be adequate and rats could provide all food since they could consume the entire pretreated log because of chipping [9]. The current rat production is order $0.1 \%$ of our food requirements [9]. With the square root of the ideal growth rate, this would take 2 years to ramp up to $100 \%$ of human food (Figure 1). Furthermore, other rodents would provide additional food.

Although more appetizing, the inherent efficiency of chickens is very similar to that of rats [34]. However, chickens have very little ability to digest cellulose, so the resultant mostly decomposed wood would have to be low in fiber. Chickens can eat their own excrement, so it might be possible for them to eat raw decomposed wood. If not, pasteurization would make the wood safe. In addition, chickens may require another source of carbohydrate. Poultry and eggs make up about $2 \%$ of the global diet now and with a realistic growth rate, this would take about 1 year to ramp up to $100 \%$ of human food (Figure 1) [9].

Depending on the severity, a catastrophe may require some relocation of people. However, we consider the worst-case scenario from a distribution perspective of no relocation. 
The refrigeration capacity would be relatively small compared to the required flow of food, but drying is feasible and would obviate refrigeration. In addition, transporting the dried food from the tropics would take a minority of current capacity [9]. The critical case for drying is industrial digestion, but it would be feasible [9].

\subsection{Stopgap Food Production: Fast food}

Some of the above nonconventional food supplies take about one year to ramp up and the minimum stored food will only last $\sim 6$ months. Therefore, for the $20^{\circ} \mathrm{C}$ catastrophes, there is a need for stopgap food production: "fast food." There are three main solutions, all utilizing nonwoody and $<\sim 1 \mathrm{~cm}$ thick woody (“thin”) biomass for fast processing: 1) extracting edible calories, 2) mushrooms, and 3) bacteria.

The human-digestible fraction of the dry weight of killed tree leaves (as opposed to depleted leaves that are shed as leaf litter) is approximately 50\% [38], and we assume this applies to all non-woody biomass that is killed. Because of all the fiber, the net calories would be relatively small [9]. However, three ways of solving this problem are 1) making tea, 2) chewing (but not swallowing the solids) and 3) grinding and pressing leaves, and then coagulating (separating out the solids from) the resultant liquid [9]. The global non-woody vegetation above ground is $~ 90 \mathrm{Gt}$ [9]; thus, even if only $1 / 3$ of this is mechanically harvestable and transported to population centers quickly, this is $30 \mathrm{Gt}$. If half is non-toxic with $5 \%$ dry matter extraction, it would be a half year supply of food (Figure 1). Industrial processing could counteract inedibility of certain plants. Additionally, the remaining material could be fed to bacteria or mushrooms, extending the supply. This could maintain food supply despite a lower amount of biomass harvest, such as would occur if the catastrophe struck during the northern hemisphere winter.

For mushroom fast food, approximately $1 / 3$ of existing building space would be required to grow all human food, though there would be complications [9]. This would generally allow normal activities to continue and is conservative because it is ignoring the possibility of using new or temporary structures, caves, and existing mines. Conservatively assuming no human weight loss, the mushrooms have to provide about five months of food. The conversion efficiency would be 5\% [9].

The less palatable fast food solution is humans eating mostly-bacteria-digested thin biomass. With the rapid doubling of bacteria in a favorable environment, this solution could provide $100 \%$ of food after only two months (Figure 1). The fiber should be relatively low because the bacteria can be mixed throughout. Nutrition from bacteria could be an issue, so it would be important to process the bacteria and couple them with other food sources.

There may be a solution that increases conversion efficiency and palatability of humans eating bacteria. The process would include chipping or grinding wood and having bacteria growing that secrete cellulase, which turns the cellulose into sugar outside their bodies. But instead of waiting until the bacteria absorbs the sugar, running water through the mixture could leach the sugar out. If humans only consumed the sugar water, the mushrooms (which can digest the lignin) could grow on the leftover material, and ruminants could eat the leftover from that. Finally, another possibility is industrially separating the bacteria from the fiber.

It is possible that these thin biomass sources could become a full solution on their own. The longer time would allow the harvest and transportation of considerably more biomass. Multiple organisms could consume wastes in series from the same biomass (including rats and chickens as they ramp up). 


\subsection{Industrial Ecology}

These solutions can work together in an industrial ecology food web as seen in Figure 2, which shows the most important food solutions and energy flows. This figure can be thought of as a transient detritus (dead material) food web (plus natural gas).

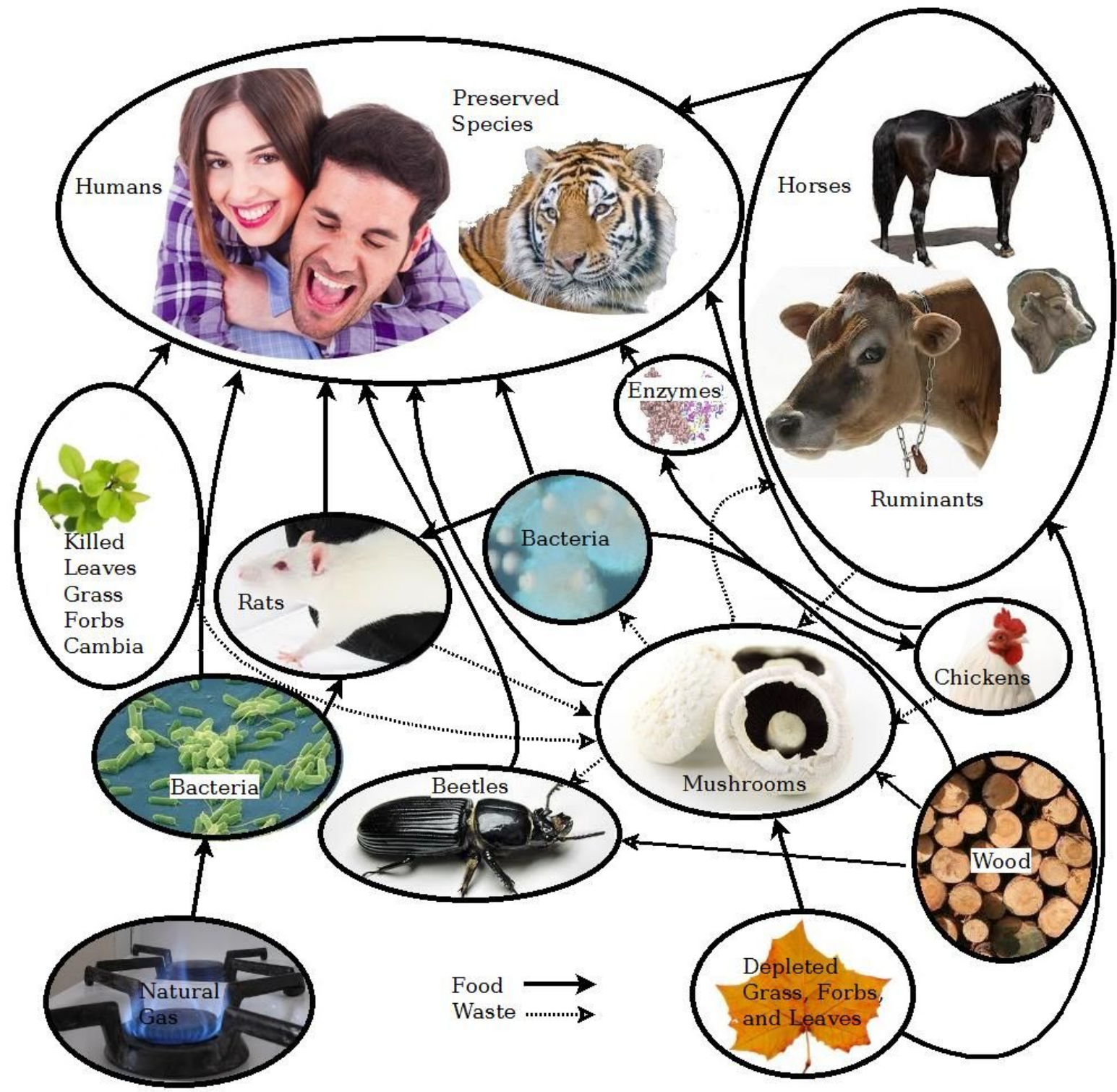

Figure 2 (color in print). Most important food sources and energy flows of the transient detritus food web. Cambia are inner barks and forbs are non-woody, non-grass plants (fishbased on photosynthesis are omitted).

\subsection{Other Considerations}


We do not believe that shipworms (a type of mollusk), termites, gribbles (a type of crustacean), earthworms, reptiles, amphibians, or non-cellulose digesting insects are promising solutions [9].

\subsubsection{Energy}

Providing energy in the sun-obscuring catastrophes should be feasible. The first part of the energy equation is the reduction in supply due to the catastrophes. We discussed the loss of solar energy in Section 1. There is likely to be a dramatic reduction in wind power, but this is also order $1 \%$ of conventional primary energy [9]. Hydropower makes up approximately 6\% of primary energy [39], so a $20^{\circ} \mathrm{C}$ crisis would result in less than a $4.5 \%$ reduction in primary energy (see section 2.6.5). Geothermal, fossil, and nuclear-based power would be largely unaffected. Subsequently, we discuss the increases in energy demand due to solving the catastrophes and conservation methods so that supply can meet demand.

In the sun-obscuring catastrophes, temperatures would fall, requiring more building heating, while reducing air-conditioning energy use. If building heating capacity were insufficient and insulation could not be added quickly enough, some relocation may be required from the areas suffering the greatest temperature loss (typically centers of continents) to warmer areas (e.g. coasts), caves, or existing mines. Farming energy use would be saved, but this would be more than compensated by the energy to fell trees, at least in the first year. In extreme scenarios, freight energy could be doubled, meaning an increase of global primary energy of approximately $9 \%$ assuming U.S. values of freight of $9 \%$ of primary energy use apply globally [40]. The energy to dry the food would be dependent on whether the foods were primarily mushrooms or leaf extraction ( $\sim 90 \%$ water), animals ( $70 \%$ water), or bacteria ( $50 \%$ water). If the drying facilities were $50 \%$ efficient based on the heat of vaporization of water, the critical case would be $2 \mathrm{Gt}$ of fuel/yr for mushrooms. If this were fossil fuel, it could make a considerable impact on consumption of the current $10 \mathrm{Gt} / \mathrm{yr}$, but if local biomass were used, the impact would be small.

Overall, the increase in fossil energy demand should only be around $10 \%$. One promising way of conserving current energy use is by reducing non-commuting personal trips, because light-duty vehicle energy use is $17 \%$ of total U.S. primary energy [40], and commuting is $27 \%$ of U.S. personal vehicle miles travelled [41]. There are many other energy-saving options that individuals and governments can implement rapidly [9].

We focused this analysis on total energy. In reality, there would not be a perfect match of the conservation ability for each fuel and the increased requirement for each fuel for catastrophe response. However, there is considerable substitutability of fuels, such as in home heating and electricity generation. Furthermore, biomass that is less valuable for food production, such as wood outside the tropics, could substitute for some fossil fuel.

Artificial-light photosynthesis is unlikely to demand much more than $4 \%$ of primary energy because of light source limitation [9].

The psychological aspects of losing the sun could be analogous to the seasonal affect disorder that many people acquire in the winter. One treatment for this is spending a considerable amount of time in high light levels. People may be able to use stray light from plant-growing operations and regardless, there is the light source cap on lighting energy use.

Wind power has grown at 25\%/yr [42], photovoltaic technology has grown at over $45 \%$ [42] and specific types of photovoltaic technologies have increased by more than double that 
(e.g. thin-film photovoltaic plants have increased by over 100\%) [43]. The catastrophe would promote even higher industrial growth rate. Therefore, we assume energy production could increase at $100 \% / y r$, meaning energy supply would be adequate. This industrial ramping could apply to other sectors.

\subsubsection{Nutrition/Taste}

Nutrition should be adequate and there are techniques to improve the taste of the food. Following the solutions outlined here, if the majority of humanity's diet were almost exclusively animals and/or typical bacteria, there would be very little carbohydrates. This could provoke the Atkins-diet response of losing weight. Therefore, supplementing with stored grain in non-worstcase scenarios, leaf extraction/chewing/tea, mushrooms, and/or industrially-produced sugar would be important. The converse problem is that insufficient protein could occur if the diet is primarily chewing/tea and industrially-produced sugar. Then the ruminants, other animals, and possibly bacteria would be important diet additions. A diet based on high-carbohydrate bacteria or leaf concentrate and reclaimed sugar could be fairly balanced in terms of macronutrients.

Mineral supplements would be easy to provide and having some variety in food sources would improve the vitamin content. Also, the recommended daily allowances of vitamins typically have a safety margin. However, in the worst-case scenario of having to provide all vitamins in the form of supplements, this is approximately $0.5 \mathrm{~g}$ per day according to the U.S. recommended daily allowance [44]. Since a small fraction of the global population currently takes full supplements, it is unlikely that industrial capacity for producing these vitamins could ramp up in time. However, engineered micro-organisms that produce each of these vitamins may scale up very quickly and consume a small amount feedstocks (future work).

Although this paper focuses primarily on technical feasibility, here we provide a brief note to address mechanisms to promote the taste acceptability of alternative food, although hunger would likely overwhelm humanity's current selective tastes given a serious catastrophe. There is considerable storage of many spices at the household level. Also, the likely drying method is by burning local biomass, which would provide smoke flavor. Furthermore, industry and bacteria produce some food flavorings, which could continue. In addition, salt will remain inexpensive, and at least some sugar could be produced through industrial digestion. Existing extensive food processing capabilities could alter the consistency of the base foods. As a last resort, artificial light could produce spices.

\subsubsection{Biodiversity}

A large amount of biodiversity could be preserved. The caloric requirements of preserving 100 individuals of every species would actually be fairly modest. For instance, 5000 mammal species with an average individual metabolic requirement less than an order of magnitude greater than a human would be equivalent to fewer than 5 million humans, more than three orders of magnitude less than keeping all the people alive. There are a tremendous number of insect species, but their individual caloric requirements are very small.

However, there are other constraints. Many animals are specialist feeders. It would be fairly straightforward to keep the carnivores alive because there would be stored meat and many of the food production options are high-protein. For specialist herbivores, humanity could preserve their food, such as bamboo for pandas. However, if this were not possible, artificial light production of plants would make preserving these species very expensive. Housing the 
large whales would be very difficult, though it may be possible to feed them in the ocean. For insects, scientists have identified only a small fraction of the total species, let alone being able to capture them and keep them alive. As a last resort, humans could preserve individuals or DNA samples, such as with cryogenic preservation. This may allow future regeneration of the species. It would be very expensive to keep plants alive, but collecting seeds would generally preserve them. Fungi, protists, bacteria and archaea (very early life forms) would probably not need human support.

\subsubsection{Forest Products}

Providing forest product (structural fiber) needs would be relatively straightforward. There would be plentiful wood feedstock in the form of dead trees outside the tropics that would be more difficult to use for food production. However, much of the forestry equipment may be utilized in the tropics for food production. Thus, it may be necessary to limit dramatically global consumption of lumber, paper, and paperboard, and this would be feasible. Solutions include substitution, recycling, and mining landfills. Other fibers, such as cotton, hemp, jute, wool and silk, would be in very short supply, but would have similar solutions.

\subsubsection{Water}

The supply of water should be adequate. Desalination could not make an important impact in the short term [9]. The absence of agricultural water demands would compensate for the reduced precipitation when the earth cools [9]. Of course, humanity would still need to produce food, but it would require far less water than plants [9]. This is because plants have considerable evaporation loss in the process of extracting carbon from the low concentration carbon dioxide in the atmosphere. The equivalent relative humidity is relatively low, even in the tropics, because of solar heating of the leaves. Hence 1 ton of grain requires 2000 tons of water [45]. Furthermore, water consumption is much higher now because of the large food losses.

However, the regional picture is more challenging. Ironically, the dry areas with extensive irrigation systems would have excess water because little irrigation would be required. It is the areas without irrigation systems where water supply would be critical. Society could transport water to these areas, but this would be energy intensive and would require extensive transportation infrastructure. Humanity could relocate some water consumption to water-rich areas, such as animals and their drinking requirements. Conservation in the electric power, industrial, and municipal sectors would be a major solution [9]. Actual human drinking water requirements are negligible compared to other uses. Unsustainable withdrawal of surface and groundwater could make up any shortfall. Therefore, with unsustainable withdrawal and the considerable quick conservation potential in the use of water by electric power, industry, and municipalities, even regional water supply appears feasible.

An additional issue is the water distribution pipes freezing due to low air temperature. Possible solutions include digging up the pipes and burying them deeper, heating the water at the water treatment plant and at people's houses for sewage, insulating the ground above the pipes, and piling soil above the pipes.

An additional issue related to water is soil erosion. In the $20^{\circ} \mathrm{C}$ catastrophe, even though there will be significantly less precipitation, because plants could not live, there would be increased soil erosion in the areas that were not frozen. This would cause short-term problems while the sun is still blocked, and long-term problems for the agricultural recovery. One potential 
short-term problem is disruption of fisheries, but there would be negligible fisheries in the $20^{\circ} \mathrm{C}$ catastrophe already because of little light. Another short-term problem is drinking water contamination, and a solution is settling ponds. Categories of solutions to the long-term problems include reducing erosion, adapting to the remaining soil, and using alternate growing environments [9].

\subsubsection{Other Problems}

At the more probable level of intensity of catastrophes, the problems of toxic gases and precipitation, dust, high temperature, conflagrations, and ionizing radiation will be more localized and have a relatively small impact on global food production. Generally, there will be a plume of dust, toxic gases, high temperature, and/or ionizing radiation emanating from the source(s). The dry deposition of the larger particles would be relatively fast. Then the small particles and soluble gases would be rained out in a few days. High temperature would also decay relatively quickly due to radiation upward and downward. An exception could be if an impact occurred on land and threw hot rocks around the world, causing widespread fires. However, the intensity of the ejecta decays with the third power of the distance [46], so it would still generally be localized. Of course dust, gases, and ionizing radiation particles could be injected into the stratosphere, and therefore have a global impact. However, the fallout rate is much lower because it would happen over years, so the intensity would be orders of magnitude lower than the local impacts. The only exception for considerable global exposure with large catastrophes would be low solubility gases, such as carbon monoxide. Therefore, the effect on food production of these factors in most cases would be relatively small in the global sense.

\subsubsection{Preparation}

There are many solutions that would require considerable preparation. We contrast these with the solutions that are the focus of this paper. As was already mentioned, storing up food is a solution that requires considerable preparation. In the same vein, larger stocks of particular animals could be intentionally kept to accelerate the time at which these food sources would attain full human food supply. Another solution that requires significant preparation is genetically engineering crops to handle lower light and temperature. A further is building checks into the food system to prevent the spread of super organisms.

Another solution that requires preparation is producing a considerable fraction of human energy from cellulosic acid-conversion biofuels, which would allow the interruption of the process at the sugar stage. This could provide all human food, assuming that the harvest of sufficient dead biomass that is compatible with the conversion process was feasible. Alternatively, industry could precondition less-compatible biomass. Scaling up this solution in non-catastrophe time could be justified on the bases of replacing finite petroleum and reducing slow climate change, though it has the disadvantages of high water and land use if it does not use residue feedstocks.

Considering the ozone problem, nanoparticles injected into the stratosphere that primarily scatter UV radiation may be able to solve the catastrophe ozone problem and not reduce light for plant growth below [47]. Work on this solution could be justified even for preventing slow climate change.

\section{Discussion}




\subsection{Moral Hazard}

Moral hazard in this context refers to the possibility that awareness of a food backup plan will result in less effort to prevent these catastrophes. Nuclear winter is the catastrophe over which humanity has the most technical control and poses the most serious threat. Mikhail Gorbachev explicitly stated that a motivating factor for reducing the nuclear arsenal of the USSR was the studies predicting nuclear winter and therefore destruction outside of the target countries [48]. However, despite the knowledge of the possibility of nuclear winter, the nuclear arsenals remain large enough to potentially cause nuclear winter. Similarly, though there is a clear and present threat of anthropogenic abrupt climate change, little has been done to effectively prevent global climate change [49]. Furthermore, the backup plan presented here could reduce the damages associated catastrophes over which humanity currently has no or very little control (e.g. supervolcanic eruptions). The only cases for which moral hazard appears to be important are the super organisms. Therefore, despite the relatively small moral hazard dilemma, we believe humanity would be much better off with a viable back up plan.

Work should be done to reduce the risks. It is not clear that possessing nuclear weapons makes a country safer [50][51]. Even 50 small nuclear weapons would have the ability to inflict similar loss of life to World War II [52], which would provide significant deterrence. This would dramatically reduce the risk of nuclear winter. There are also other steps to reduce the risk of nuclear winter [16].

\subsection{Policy Implications and Future Work}

This analysis has focused primarily on the technical feasibility of food supply in extreme circumstances. However, there are several policy implications during both normal times, but also to prepare to feed everyone in even the most challenging of situations.

\subsubsection{Lessons for Non-Catastrophe Times}

Despite the enormous global catastrophic risks summarized in Table 1, this paper has shown that it is technically viable to maintain the entire human population with existing vegetation/fossil fuels even in extreme global catastrophes. Unfortunately, even in these peaceful times with relatively minor challenges humanity fails to feed everyone. 870 million people do not have enough to eat [25] and under-nutrition contributes to over six million deaths of children under five each year in developing countries. In the regions where hunger-related death is most common and the poor do not have access to conventional agricultural resources, humanity could utilize some of the solutions outlined here directly. There are techniques of increasing the use of waste products for producing animal cellulose digesters. As mushrooms can grow on waste products, people should recognize them as an environmentally friendly food source. This could increase their consumption, reducing land and water use. There is currently a very large supply of materials that mushrooms could utilize (but many cellulose digesters cannot) in the form of silviculture (wood harvesting) residues. For cellulose digesters, the practice of feeding excrement from other animals could be expanded. With this high-nitrogen food source, lower nitrogen sources could be used in addition, such as agricultural residues that are not green and tree leaves that have been depleted of their nutrients (and shed). These practices have the potential of dramatically reducing the ecological footprint associated with cellulose digesters, which form a considerable fraction of the food and overall ecological footprint. Also, extracting human food from leaves and other agricultural residues would reduce environmental impact. 
Macronutrient fertilization of the ocean could produce a considerable amount of food. This would take pressure off terrestrial ecosystems, preserving biodiversity. Also, by preventing forest destruction, $\mathrm{CO}_{2}$ release would be prevented. Furthermore, some of the carbon produced in the ocean would sink to the ocean floor, sequestering $\mathrm{CO}_{2}$. Moreover, policies could promote the dissemination of clear instructions on extracting human food from leaves other agricultural residues to those most in need.

\subsubsection{Future Work}

Future work would improve significantly the technical viability of all the solutions analyzed here for catastrophe scenarios. This analysis has focused on technical feasibility of food supply; however, future work is needed to improve existing technologies, to test solutions and to take into account the economics, politics, sociology (e.g. religion) to make a backup food supply feasible for humanity. First, there is the issue of the poor of the world not being able to afford high-priced food, with possible solutions of subsidies and loans. Then there is the issue of maintaining global cooperation because trade would be very important. Conflict may be in some countries' best interests, so this would be difficult. Future work should estimate labor for all of these with realistic workers. However, generally the solutions can utilize mechanical means (e.g. chainsaws, not manual saws) so we do not expect labor to limit the technical feasibility.

Future work also includes making sure there are bacteria that produce large amounts of each vitamin required for humans. Micronutrient supplements for food animals would be more difficult than for humans, so this requires further work.

Future climate modeling work could investigate scenarios with nearly complete blocking of sunlight globally. Also, reducing the uncertainty in the regional impacts would be valuable.

The interaction of food catastrophes is generally less likely, but would be more severe, so it is important to study in the future. Projecting future capability of handling catastrophes would also be valuable (e.g. changes in population and industrial capacity).

There is great urgency to perform follow-up research that increases the probability of success of these solutions. For instance, if a research project increased the probability of most people surviving versus most people dying by only $0.1 \%$ given a catastrophe, every day of delay of completion of the project would cost an order of magnitude 10 lives [9]. Furthermore, by reducing the probability of extinction, many more future lives could be saved [53].

\section{Conclusions}

Storing food is the only historical solution for a global loss of food supply and storing food rapidly to prepare for these risks would likely aggravate the current malnutrition problem. In this paper, we propose seven independent routes, 10 promising options, and 30 total options for providing the food necessary to support the entire human population. The seven promising routes to meet human food energy demands are: natural light (fishing); methane-digesting bacteria; enzyme-produced food; extracting food from thin biomass and then mushroom and cellulose digester conversion; thin biomass converted to bacteria; thick biomass (trees) converted to bacteria; and trees converted to mushrooms, cellulose-digesting beetles, rats, and/or chickens. For the $20^{\circ} \mathrm{C}$ loss catastrophes, fishing is unlikely to be successful and fast food would be required if the catastrophe struck at low grain supplies, reducing the number of independent options. However, relaxing the requirement that an option provide all of human food because there will be multiple sources would increase the feasibility. Though only partial solutions in the 
first five years, ruminants could become dominant in the latter half of a decade-long catastrophe. If the thin biomass is consumed in the first five years, then the thick biomass could generally be used in the successive five years, and vice versa, especially with natural drying. Therefore, this order-of-magnitude analysis shows that it is technically feasible to feed all humans and save a considerable number of species in all but the most extreme catastrophes.

\subsection{Most Extreme Catastrophes}

Even in the most extreme catastrophes, such as a very large asteroid or comet that could result in the burning of nearly all above-ground vegetation, there may still be some viable routes to feed everyone. Very large impacts would increase atmospheric temperature considerably immediately after impact [54]. Therefore, this would require some advance warning, but this would generally be the case because of the size of the impactor. Possible solutions to the temperature increase for buildings include consolidating people into fewer buildings, rejecting heat to the ground, using air compressors for cooling (compressing air, letting it cool down, and then decompressing to go to low temperatures), and relocating to cooler areas such as caves, existing mines, or even onto ice. Also, there would be intense thermal radiation caused by rock particles [54], so insulating on the outside of buildings would protect from this radiation and facilitate longer-term building cooling. Furthermore, industry could retrofit vehicles for the higher temperatures. Toxic gases could be a problem globally, but possible solutions include filtration (e.g. activated carbon), destruction via catalysts, and consumption by bacteria.

As for food, stored food could be removed from the areas that will be most affected and protected. Methane-digesting bacteria would still be promising. Also, enzymatic conversion is efficient, so the feedstock requirement is small. Vegetation that naturally did not burn, biomass that humans protected, or peat (its high water content would protect it and it still generally contains considerable amounts of cellulose and hemicellulose [55]) could meet this requirement.

It is conceivable that it takes more than one decade to solve the crop-killing scenarios (and continental basalt flows may last centuries). One route to extending the existing vegetation supply is ramping up industrial digestion, which is considerably more efficient than biological methods. Again, methane-digesting bacteria would be feasible. Furthermore, with the greater lead time, it is possible that industry could ramp up synthetic food production to provide all of human food. The energy source could be fossil fuel, nuclear or renewable energy, because these scenarios would generally not involve blocking the sun.

\subsubsection{Overall Conclusion}

Given the considerable chance that a catastrophe that dramatically reduces food supply may strike at any time, it is imperative to perform follow up research. This could be a topic for the International Food Policy Research Institute, The World Bank and other international organizations to publicize to increase international awareness and research.

Acknowledgments: The authors would like to acknowledge helpful discussions with Joseph Geddes, Carl Shulman, Anders Sandberg, David Fox, Glenn Prestwich, E. Wayne Askew, Robert Andrews, Stuart Armstrong, Kerri Pratt, Sean Brandt, Aaron Socha, Seth Baum, Geoffrey Livesey, Anton Sonnenberg, Barbara Bentley, Ronald Benner, David Bignell, Aleksandra Walczyńska, Jason English, Peter Paalvast, Jill Stone, Marcel Dicke, Robert Elkin, James Dunn, 
Preprint: DC Denkenberger \& JM Pearce, Feeding Everyone: Solving the Food Crisis in Event of Global Catastrophes that Kill Crops or Obscure the Sun. Futures 72: 57-68 (2015). DOI:http://dx.doi.org/10.1016/j.futures.2014.11.008

John Comerford, Tablado Zulima, Jay Stauffer, Jian Shi, Geoffrey Hoy, Karri Bertram, Saravanamuth Vigneswaran, and Ian Rowland.

\section{References:}

[1] P. Valdes, Built for stability, Nat Geosci. 4 (2011) 414-416. doi:10.1038/ngeo1200.

[2] C.C. Mann, Genetic engineers aim to soup up crop photosynthesis, Sci. 283 (1999) 314-316.

[3] J.P. Dudley, M.H. Woodford, Bioweapons, biodiversity, and ecocide: Potential effects of biological weapons on biological diversity, Biosci. 52 (2002) 583. doi:10.1641/0006-3568(2002)052[0583:BBAEPE]2.0.CO;2.

[4] M.A. Aizen, L.A. Garibaldi, S.A. Cunningham, A.M. Klein, How much does agriculture depend on pollinators? Lessons from long-term trends in crop production, Ann. Bot. 103 (2009) 1579-1588.

[5] G. Church, Safeguarding biology, Seed. 20 (2009) 84-86.

[6] H. Saigo, Agricultural biotechnology and the negotiation of the biosafety protocol, Georget. Int Env. Law Rev. 12 (2000).

[7] N. Bostrom, M.M. Cirkovic, eds., Global Catastrophic Risks, Oxford University press, New York, 2008.

[8] Alan Robock, Luke Oman, Georgiy L. Stenchikov, Nuclear Winter Revisited with a Modern Climate Model and Current Nuclear Arsenals: Still Catastrophic Consequences, J. Geophys. Res. - Atmospheres. (2007).

[9] Author, Forthcoming Book, Elsevier, 2015.

[10] E.C. Oerke, Crop losses to pests, J Agric Sci. 144 (2006) 31-43.

[11] S. Kilman, Superweed outbreak triggers arms race, Wall Str. J. (2010).

[12] L.V. Madden, M. Wheelis, The threat of plant pathogens as weapons against U.S. crops, Annu Rev Phytopathol. 41 (2003) 155-176. doi:10.1146/annurev.phyto.41.121902.102839.

[13] S. Solomon, D. Qin, M. Manning, Z. Chen, M. Marquis, K.B. Averyt, et al., Summary for policymakers, Intergovernmental Panel on Climate Change, 2007.

[14] R.B. Alley, J. Marotzke, W.D. Nordhaus, J.T. Overpeck, D.M. Peteet, R.A.J. Pielke, et al., Abrupt climate change, Sci. 299 (2003) 2005-2010.

[15] M.E. Hellman, Risk analysis of nuclear deterrence, Bent Tau Beta Pi. (2008).

[16] A.M. Barrett, S.D. Baum, K.R. Hostetler, Analyzing and reducing the risks of inadvertent nuclear war between the United States and Russia, Sci Glob. Secur. 21 (2013) 106-133.

[17] P.R. Ehrlich, A.H. Ehrlich, Can a collapse of global civilization be avoided?, Proc R Soc Lond. Ser B. 280 (2013).

[18] E.L. Rezende, J.E. Lavabre, P.R. Guimaraes Jr, P. Jordano, J. Bascompte, Non-random coextinctions in phylogenetically structured mutualistic networks, Nat. Lett. 448 (2007).

[19] S.L. Postel, Water for food production: Will there be enough in 2025?, Biosci. 48 (1998) 629-637.

[20] Millennium Ecosystem Assessment, Ecosystems and Human Well-Being: Current State and Trends, Island Press, United States, 2005.

[21] G. Olah, A. Goeppert, G.K.S. Prakash, Chemical recycling of carbon dioxide to methanol and dimethyl ether: From greenhouse gas to renewable, environmentally carbon neutral fuels and synthetic hydrocarbons, J. Org. Chem. Perspect. 74 (2009).

[22] J.W. Erisman, M.A. Sutton, J. Galloway, Z. Klimont, W. Winiwarter, How a century of ammonia synthesis changed the world, Nat Geosci. 1 (2008) 636-639.

[23] T.H. Tietenberg, Environmental and natural resource economics, 5th ed., Addison-Wesley, Reading, MA, 2000.

[24] M.J. Mills, O.B. Toon, R.P. Turco, D.E. Kinnison, R.R. Garcia, Massive global ozone loss predicted following regional nuclear conflict, Proc Natl Acad Sci USA. 105 (2008) 5307-5312.

[25] United Nations Children's Fund (UNICEF), The state of the World's children, New York, 2006.

[26] J. Wallace, P. Hobbs, Atmospheric Science, Academic Press, New York, 1977.

[27] Food and Agriculture Organization (United Nations), Global Forest Resources Assessment, 2000.

[28] E. O'Driscoll, Roundwood supply, wood energy and related issues in the UNECE region, Coford Connects. Processing / Products 14 (2008). 
Preprint: DC Denkenberger \& JM Pearce, Feeding Everyone: Solving the Food Crisis in Event of Global Catastrophes that Kill Crops or Obscure the Sun. Futures 72: 57-68 (2015). DOI:http://dx.doi.org/10.1016/j.futures.2014.11.008

[29] K.W. Ragland, D.J. Aerts, A.J. Baker, Properties of wood for combustion analysis, Bioresour. Technol. 37 (1991) 161-168.

[30] C. Timmreck, H.-F. Graf, D. Zanchettin, S. Hagemann, T. Kleinen, K. Krüger, Climate response to the Toba super-eruption: Regional changes, Quat. Int. 258 (2012) 30-44.

[31] P. Langan, S. Gnanakaran, K.D. Rector, N. Pawley, D.T. Fox, D.W. Chof, et al., Exploring new strategies for cellulosic biofuels production, Energy Env. Sci. 4 (2011) 3820-3833.

[32] P.J. Van Soest, Nutritional Ecology of the Ruminant, Cornell University Press, Ithaca, NY, USA, 1994.

[33] R. Spinosa, Fungi and sustainability, Fungi. 1 (2008).

[34] T. C. Byerly, Efficiency of Feed Conversion, Science. 157 (1967) 890-895.

[35] M.A. Belewu, K.Y. Belewu, Cultivation of mushroom (Volvariella volvacea) on banana leaves, Afr J Biotechnol. 4 (2005) 1401-1403.

[36] R. Benner, J. Lay, E. K’nees, R.E. Hodson, Carbon conversion efficiency for bacterial growth on lignocellulose: Implications for detritus-based food webs, Limnol Ocean. 30 (1988) 1514-1526.

[37] R.B. Johnson, D.A. Peterson, B.M. Tolbert, Cellulose metabolism in the rat, J Nutr. 72 (1960) 353.

[38] S. Jacquemoud, S.L. Ustin, J. Verdebout, G. Schmuck, G. Andreoli, B. Hosgood, Estimating leaf biochemistry using the PROSPECT leaf optical properties model, Remote Sens Env. 56 (1996) 194-202.

[39] M. Lucky, Global Hydropower Installed Capacity and Use Increase, World Watch, 2012.

[40] U.S. Department of Energy, Energy Efficiency and Renewable Energy, Transportation Energy Data Book, 30th ed., U.S. Department of Energy, Springfield, VA, 2011.

[41] U.S. Department of Transportation, National household transportation survey, 2001.

[42] D.M. Kammen, The rise of renewable energy, Sci Am. 294 (2006) 84-93. doi:10.1038/scientificamerican0906-84.

[43] Author, Title, Journal. 38 (2010) 1969-1978.

[44] J.J. Otten, J.P. Hellwig, L.D. Meyers, Dietary reference intakes (DRIs), The National Academies Press, 2006.

[45] A.Y. Hoekstra, A.K. Chapagain, Water footprints of nations: Water use by people as a function of their consumption pattern, Water Resour Manag. 21 (2005) 35-48.

[46] G.S. Collins, H.J. Melosh, R.A. Marcus, Earth impact effects program: A Web-based computer program for calculating the regional environmental consequences of a meteoroid impact on Earth, Meteorit Planet Sci. 40 (2005) 817-840.

[47] E. Teller, R. Hyde, L. Wood, Active Climate Stabilization: Practical Physics-Based Approaches to Prevention of Climate Change, in: Washington, D.C., 2002.

[48] O. Toon, A. Robock, R. Turco, Environmental consequences of nuclear war, Phys Today. 61 (2008) 37-42.

[49] G.W. Yone, R.D. Lasco, Q.K. Ahmad, N.W. Arnell, S.J. Cohen, C. Hope, et al., Perspectives on climate change and sustainability, Intergovernmental Panel on Climate Change, 2007.

[50] S.I. Schwartz, Atomic Audit: The Costs and Consequences of U. S. Nuclear Weapons Since 1940, Brookings Institution Press, Harrisonburg, VA, 1998.

[51] T.V. Paul, Power Versus Prudence: Why Nations Forgo Nuclear Weapons, McGill Queens University Publisher, 2000.

[52] O.B. Toon, R.P. Turco, A. Robock, C. Bardeen, L. Oman, G.L. Stenchikov, Atmospheric effects and societal consequences of regional scale nuclear conflicts and acts of individual nuclear terrorism, Atmos Chem Phys. 7 (2007) 1973-2002.

[53] N. Bostrom, Astronomical Waste: The Opportunity Cost of Delayed Technological Development, Utilitas. 15 (2003) 308-314.

[54] H.J. Melosh, N.M. Schneider, K.J. Zahnle, D. Latham, Ignition of global wildfires at the Cretaceous/Tertiary boundary, Nat. 343 (1990) 251-254.

[55] J.P. Andriesse, Nature and management of tropical peat soils, FAO - Food and Agriculture Organization of the United Nations, Rome, Italy, 1988. 